\title{
Creative Thinking in Decision Making: A Bibliography
}

\section{Carl H. Losse and Arlyle Mansfield Losse}

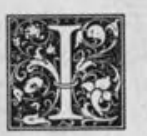

$\mathrm{n}$ a time when communication techniques are rapidly being transformed, librarians must cope with a variety of new problems. As Charles McClure and Alan Samuels have noted, "Change requires climates that are receptive to innovation. ${ }^{\prime 1}$ Alert persons in the field of information science will be eager to examine new ways to enhance their problemsolving skills.

Modern approaches to decision making tend to include not only the wellestablished linear (logical) modes of thinking but also thinking that deviates sufficiently from rigid patterns to allow scope for metaphor and intuitiveness. Perhaps the chief use of metaphorical thinking is in the generation of ideas. Intuition, a tool that has proved useful for eminent artists and scientists alike, needs to be submitted to analysis before final decisions are made.

As Charles Martell has observed, "Some trends in the information world ... seem to demand not coping but creative responses. ${ }^{\prime 2}$ Linear thinking has dominated the library world so extensively that readers need to turn to other fields for new approaches to decision making. Librarians and information specialists may well glean helpful concepts of creative-thinking techniques from the following selective bibliography.
Anthony, William P., Walt Wheatley, and Nick Maddox. "Better Management through the Mind's Eye." Association Management 37:86-90 (Nov.1985).

Typical activities that are aided by purposeful mental imagery are goal setting, creative problem solving, and communications. In focusing on problems rather than symptoms, guided imagery facilitates workable, creative solutions.

Armes, Nancy. "For Creative Leaders: False Starts, Happy Mistakes." Community and Junior College Journal 54:22-25 (Oct. 1983).

To encourage creativity among careerists, Armes advocates three strategies: changing the tempo of work, forming support groups, and finding professional resource persons to help.

Basadur, Min, and Carl T. Finkbeiner. "Measuring Preferences for Ideation in Creative-Problem-Solving Training." Journal of Applied Behavioral Science 21, no.1:37-49 (Feb. 1985).

Realizing that some theorists allow judgmental thinking to be expressed during group idea production, authors Basadur and Finkbeiner incline toward deferring attitudinal judgments until ideas have been generated. The writers consider creative thinking a two-step activity: ideation and valuation.

Carl H. Losse and Arlyle Mansfield Losse of Milwaukee, Wisconsin, are retired librarians and life members of ALA. In the Milwaukee Public Library System, Carl Losse was formerly Special Services Librarian to Subject Areas, and Arlyle Losse was a librarian in the Art/Music/Recreation department. 
Conrath, Jerry. "The Imagination Harvest: Training People to Solve Problems Creatively." Supervisory Management 30 , no.9:6-10 (Sept. 1985).

Breaking down creative problem solving into six phases, Conrath emphasizes defining a problem rather than concentrating on irritants (symptoms). He suggests classifying perceived barriers to creative thinking as personal and organizational.

\section{The Council of Scholars of the Library of}

Congress. Creativity: A Continuing Inventory of Knowledge. Washington, D.C.: Library of Congress, 1981.

The council contends that for innovation to be creative it must be nontrivial, valuable, or profitable. A perceived need among thinkers is to promote creative borrowing - "the process by which ideas and modules in one field stimulate creativity in another."

Davidson Jeffery P. "A Way to Work in Concert." Management World 15:8-10 (Mar. 1986).

Team resolution of issues is prudent because "more participation leads to more creative thinking, which often leads to more feasible alternatives," Davidson suggests. However, he warns against a group's settling for a harmonious decision rather than focusing on a truly innovative approach to problem solving.

DeBono, Edward. Lateral Thinking: Creativity Step by Step. New York: Harper, 1970.

Lateral thinkers free information that can be arranged in a new way by changing the habitual method of looking at a specific situation. Not concerned with proof, lateral thinking concentrates upon generating ideas that may ultimately be helpful in decision making.

DeBono, Edward. New Think: The Use of Lateral Thinking in the Generation of New Ideas. New York: Basic Books, 1968.

The author of New Think believes that the mind's ability to create new ideas and ways of looking at things is the basis of progress. Sometimes situations related to play can provide a helpful background for the development of future ideas. DeBono considers creative thinking a special part of lateral thinking. As lateral thinking generates ideas and vertical thinking develops them, both have importance in decision making.

DeBono's Thinking Course. 10-part television series. London: BBC, 1983.

This television series merited attention by providing many helpful devices to spark creative thinking. For example, DeBono illustrated how a word selected at random (perhaps a certain page and column position in any available dictionary) can generate ideas. Another useful device for making decisions is the "simple matrix," in which people screen positive features of alternative actions in terms of three essentials that the solution must have. Choosing targets is a thoughtprovoking method whereby decision makers name what needs to be achieved and then attempt strategy (broad guidelines) and tactics (moment-to-moment variations) to attain their aim.

Edson, Lee. "Intuition." Across the Board 19:7-10 (June 1982).

Edson outlines five phases in intuitive problem solving: preparation, frustration, incubation, illumination, and elaboration.

Gordon, William J. J. The Metaphorical Way of Learning and Knowing. Cambridge, Mass: Porpoise Books, 1971. (Especially consulted, introduction and section 1.)

Gordon believes that the most significant element of the creative process in problem solving is "making the familiar strange." The author describes three metaphorical forms that aid innovative thinking: direct analogy, personal analogy, and compressed conflict. Building upon analogies, the compressed conflict (a noun preceded by a seemingly incongruous modifier) tends to suggest new directions of thought.

Gordon, William J. J. Synectics: The Devel- 
opment of Creative Capacity. New York, Harper, 1961.

Synectics theory is based upon the ability of people to learn metaphorical attitudes of mind. Creativity involves playing with associations (ideas and images) that may seem irrelevant to a specific problem. Maintaining that a functional group has advantages over an individual in problem solving, the author quotes conversations of selected groups engaged in creative thinking. Sometimes group participants must temporarily disbelieve scientific laws in order to derive a new viewpoint.

\section{Gordon, William J. J., and Tony Poze.}

"Conscious/Subconscious Interaction in a Creative Act." The Journal of Creative Behavior 15, no.1:1-10 (First Quarter 1981).

This discussion of analogy formation helps the nonexpert perceive how illumination or conceptual breakthrough occurs in creative thinking. The authors suggest that creative subconscious performs analysis by image.

Graham, John W. "Getting the Best from your Creative Staff." Industrial Design 26:52-54 (Sept./Oct. 1979).

Written from the viewpoint of a director of creative workers, this article recognizes the need to allow peaks and valleys of activity, rather than requiring a steady high level of production. Graham believes that managers should provide deadlines that will motivate anxious workers to overcome information retrieval barriers and gain access to ideas from factual contexts not usually available.

\section{"Handling the Barriers to Creativity; or,} How to Become More Like a Raccoon." Nation's Business 70: 68-69 (Jan. 1982). Excerpted from Buggie, Frederick D. New Product Development Strategies. New York: American Management, 1981.

Interpreting creativity as "the ability to generate new options," the author mentions six corporate hindrances and offers fifteen suggestions for overcoming those barriers. The concisely presented theories of Frederick D. Buggie provide a practical approach to achieving innovative decision making.

Huyghe, Rene. "On the Contribution of Visual Art to the Way of Thinking." Leonardo 14, no.4:314-15 (Autumn 1981).

Lamenting the current rupture between arts and sciences, Huyghe feels that people of our time should not limit themselves to the scientific way of thinking. He affirms that artistic sensitivity, intuition, and imagination can supply complementary factors for the exploration of reality.

Kikuchi, Makoto. Creativity and Ways of

Thinking: The Japanese Style." Physics Today 34:42-45 and 48-51 (Sept. 1981).

When decision making needs to be done by a group that includes not only adherents to a logical approach but also thinkers who rely on pattern recognition, the information contained in this article may inspire patience among discussion participants. Kikuchi show how cultural backgrounds of persons affect their thinking.

Miles, Mary. "Going with Your Gut Feeling." Computer Decisions 14:206, 208, 210 (Nov. 1982).

Though Mary Miles believes that intuition may help in decision making, she advises submitting hunches to careful examination. Test questions designed to probe the validity of ideas based on intense feelings are presented. Problem solvers should back up their hunches with all available objective knowledge before reaching a final decision.

Moyers, Bill D. "Defining Creativity for Everyone to See Wasn't Exactly Easy." Smithsonian 12:64-73 (Jan. 1982).

In preparing for the 1982 TV series "Creativity with Bill Moyers," the man who had been press secretary to President Johnson learned that "there may be as many creative processes as there are creative people." Moyers warns against excessive regard for everything new, because novelty must, to be really creative, dem- 
onstrate significance by generating insight.

Osborn, Alexander F. Applied Imagination; Principles and Procedures of Creative Problem Solving. 3d rev. ed. New York: Scribner, 1963.

The theme "To think intelligently is to think creatively" is carried out with many variations in this comprehensive book. Osborn emphasizes the kind of creativity that involves generation of ideas. He believes that creative problem solving ideally comprises fact finding, idea finding, and solution finding. In nearly all idea finding, association of ideas (reintegration) plays an important role.

After multiple tentative ideas have been gained, they usually must be screened, evaluated, and developed before a final solution is adopted. As spurs to idea production, the author suggests asking questions that concern adaptation, modification, and substitution of a component. Questions about magnification, minification, rearrangement, reversal, and combination may also help creative thought on a subject. Osborn concludes that "imagination can be the key to the solution of almost any kind of problem."

\section{Parnes, Sidney J., and Harold F. Harding,} eds. A Source Book for Creative Thinking. New York: Scribner, 1962. (Especially consulted, section 21, "Useful Creative Techniques," by John E. Arnold, p.251-68.)

After mentioning other creative approaches, Arnold offers his own checklist: "Question, observe, associate, and predict." He considers brainstorming one of the most effective tools of organized creative activity.

Pollock, Ted. "How to Ask Creative Questions." Consulting Engineer 65:50 (Sept. 1985).

Pollock mentions four times during the problem-solving sequence when it is vital to ask questions. He also recommends uncovering creative opportunities in familiar surroundings and continuing to inquire about the why of things.
Raudsepp, Eugene. "The Hunch Factor." Executive Female 6:20-23 (July/ Aug.1983).

Indicating that business and technology have profited from intuitive perceptions, Raudsepp affirms that intuition and logical thinking typically complement each other. Psychologist Frances E. Vaughan's guidelines for awakening intuition are presented. These include intention, relaxation, trust in oneself, openness, detachment, and other supportive factors.

Raudsepp, Eugene. "Intuition: A Neglected Decision-Making Tool." Machine Design 52:91-94 (Sept. 25, 1980).

Where there is necessity to reach a decision that involves numerous complex, interrelated factors, an intuitive approach may be advantageous. Intuition should not be ignored, but rather, should be used as an effective supplement to analytical thought. Raudsepp offers five suggestions for improving intuitive capability.

Raudsepp, Eugene. "101 Ways to Spark Your Employees' Creative Potential." Office Administration and Automation 46:38 (Sept. 1985).

Among many guidelines for improving innovative achievement are suggestions to help subordinates perceive problems as challenges; to focus creative abilities on goals; and to consider creativity as a necessary aspect of complete organizational policy.

Rosner, Stanley, and Lawrence E. Abt, eds. The Creative Experience. New York: Dell, 1972. (Especially consulted, "Conclusion and a Review of the Literature on Creativity," p.377-92.)

Remarks by achievers whom the editors interviewed suggest that the creative process is similar in both art and science. Creative persons tend to become excited and feel a sense of urgency about their work. They also possess questioning minds. Intellectual independence is considered essential for effective creative thinking.

Rubinstein, Gwen. "Whole Brain Man- 
agement." Association Management 37:112-16 (Aug. 1985).

The author suggests that one way to integrate logical and intuitive skills is to let intuition guide decision making after all of the facts have been examined. Rubinstein quotes from Weston Agor, who advises eliminating such blocks to intuitiveness as tension, strict adherence to rules, considering the status quo as excellent, and insistence on practicality.

Slocum, John W., Jr., and Don Hellriegel. "A Look at How Managers' Minds Work." Business Horizons 26:58-68 (July/Aug. 1983).

Slocum and Hellriegel find that one of the differences between sensing and intuitive types of managers is that the sensation oriented are concerned with what can be achieved in the immediate present; intuitors like to take a long-range view of situations. The authors admit that there is "no one best problem-solving style."

Smith, Emily T. "Are You Creative?" Business Week 2914:80-84 (Sept. 30, 1985).

Smith quotes William Herrmann's definition of creativity as "a combination of different types of thinking-analytical, verbal, intuitive, and emotional." To spur innovation, practical people may ask "what if?" about any situation. Analogy often proves helpful when decision makers consider how a similar problem is solved in nature.

White, Richard L. "Keys to Creativity." Design News 41:17 (Sept. 23, 1985).

Richard L. White, interviewer, considers freethinking the "linchpin of creativity." Innovator Matthew Holtzberg believes that every new idea is basically a dream. Robert Jarvik deems cooperative interaction with people especially important. Isaac Asimov declares, "Failure can guide you to success." Carl Marvel admits that a good sense of humor is essential in creative endeavor.

Wiest, Jerome D. "Heuristic Programs for Decision Making." Harvard Business Review 44:129-43 (Sept./Oct. 1966).

For purposes of this article, heuristic means an aid to discovering a solution to a problem. For example, a manager may devise and follow this technique: "Reschedule noncritical jobs, if possible, in order to free resources for scheduling critical jobs." Through combining various heuristics in a computer program, the planner may shorten the time needed to arrive at effective decisions.

\section{REFERENCES}

1. Charles R. McClure and Alan R. Samuels, "Factors Affecting the Use of Information for Academic Library Decision Making," College \& Research Libraries 46:483-98 (Nov. 1985).

2. Charles R. Martell, "Creative Behavior in Libraries," College \& Research Libraries 46:293-94 July 1985). 